\title{
Contribuição a uma Tipologia das Formas de Desrespeito: Para Além do Modelo Hegeliano-Republicano
}

\author{
João Feres Jr.
}

E ste artigo é uma contribuição crítica para um dos debates mais candentes no pensamento político contemporâneo: a questão do reconhecimento. O intento aqui não é somente mostrar os problemas embutidos no tratamento atual mais sistemático dessa questão, elaborado pelo filósofo alemão Axel Honneth, mas também propor um modelo analítico de identificação da falta de reconhecimento (desrespeito) no uso comum da linguagem ${ }^{1}$. Como pretendemos demonstrar, nosso modelo permite uma análise mais ampla da questão e, ao mesmo tempo, mais adequada à condição de heteronomia vigente no mundo de hoje. Ademais, ele evita certos vícios perpetuados pela abordagem hegeliano-republicana de Honneth.

Na primeira parte do artigo, expomos a tipologia das formas de desrespeito elaborada por Honneth e, logo em seguida, levantamos uma série de problemas nela contidos. A partir dessa crítica, e com a ajuda da teoria semântica dos pares de contraconceitos assimétricos de Reinhart Koselleck, propomos na seção seguinte uma nova tipologia das formas de desrespeito. A construção dessa tipologia envolve um trabalho de reforma e alteração razoavelmente extenso da teoria koselleckiana. Finalmente, concluímos apontando para as vantagens

DADOS - Revista de Ciências Sociais, Rio de Janeiro, Vol. 45, no 4, 2002, pp. 555 a 576. 
João Feres Jr.

comparativas que o nosso modelo apresenta em relação à concepção de Honneth.

O reconhecimento é hoje um dos tópicos mais debatidos no meio acadêmico dos países chamados "desenvolvidos". Não raro, o problema é colocado em termos da coexistência entre uma sociedade multicultural e um regime político democrático liberal. Ao discutir a relação entre reconhecimento e multiculturalismo, Charles Taylor, um dos intelectuais mais ativos nesse debate, declara: "Falta de reconhecimento [nonrecognition ou misrecognition] pode ser prejudicial, pois é uma forma de opressão que aprisiona o indivíduo em um modo-de-ser tolhido, falso e distorcido" (Taylor e Gutmann, 1994:25)².

Axel Honneth aborda a questão de maneira similar:

"O uso de conceitos negativos desse tipo [desrespeito] deve ser considerado uma injustiça não apenas porque ele priva pessoas de sua liberdade de ação ou lhes é insultante, mas também porque ele interfere negativamente na compreensão que as pessoas têm de si próprias uma compreensão que é adquirida através de meios intersubjetivos" (1992:189).

Devemos deixar claro de antemão que tanto Taylor como Honneth trabalham da perspectiva do pragmatismo lingüístico, ou seja, com a idéia de que o significado das formas lingüísticas é determinado pelo seu uso $^{3}$. Dado que o uso da linguagem sempre se dá dentro de uma comunidade lingüística, o significado é gerado no entendimento intersubjetivo. Nesse contexto, o reconhecimento deve ser compreendido não como fenômeno psicológico pré ou extralingüístico, mas como um problema constituído no uso eminentemente intersubjetivo da linguagem corrente.

Honneth dispensa à questão do reconhecimento um tratamento muito mais sistemático que Taylor ${ }^{4}$. Em "Integrity and Disrespect", esse autor propõe uma tipologia das formas de reconhecimento baseada nas idéias de Ernst Bloch. Para Bloch, a dignidade humana é uma questão de teoria moral que deve ser estudada não a partir de alguma noção metafísica positiva de respeito, mas a partir de condições concretas de desrespeito e injúria. Honneth discorda dessa idéia, e defende a possibilidade de uma teoria positiva do reconhecimento. 
"Se para o conceito de dignidade, a integridade completa do homem só pode ser aproximada através da determinação de formas de insulto e desrespeito da pessoa, então devemos concluir que a constituição da integridade humana depende da experiência do reconhecimento intersubjetivo" (Honneth, 1992:188).

Antes, porém, como trabalho preliminar de elaboração de uma teoria positiva do reconhecimento, Honneth propõe uma tipologia tripartite das formas de desrespeito. O primeiro caso são os mau-tratos físicos, que ocorrem quando a pessoa é alienada do controle sobre seu próprio corpo. A tortura e o estupro são os exemplos clássicos desse insulto. Para Honneth, o maior dano causado por essa forma de desrespeito não é a dor física, mas a humilhação da perda da autonomia corporal, que, mais tarde, se converte em perda de autoconfiança, estranhamento em relação ao mundo e insegurança no contato com outras pessoas. Em suma, a pessoa é ferida em sua auto-imagem. Honneth denomina essa forma de desrespeito de "morte psicológica". O segundo tipo de desrespeito corresponde à negação de direitos a uma pessoa. Segundo Honneth, enquanto membro de uma sociedade, a pessoa se entende possuidora de uma série de direitos que espera ver respeitados pelos outros membros. Uma vez que qualquer desses direitos lhe é repetidamente negado, a pessoa sente-se rebaixada a uma posição de inferioridade moral, pois o que pressupõe a igualdade de direitos é a capacidade que cada um tem de formular julgamentos morais. Tal insulto deprime a auto-estima da pessoa no tocante à capacidade que ela tem de se relacionar com os outros de igual para igual. Honneth designa essa forma de desrespeito de "morte social". A terceira forma consiste na depreciação do estilo de vida individual ou grupal.

"A 'honra', a 'dignidade', ou, para usarmos uma palavra moderna, o 'status' de uma pessoa, corresponde ao grau de aceitação social, dentro do horizonte de tradições culturais de uma dada sociedade, dos métodos de auto-realização escolhidos pela pessoa. Caso a hierarquia de valores sociais seja estruturada de modo a imprimir um rótulo de inferioridade e deficiência sobre suas convicções e estilos de vida, essa pessoa é impedida de atribuir valor social às suas habilidades" (idem:191).

Nesse caso, o desrespeito, segundo Honneth, deprime a auto-estima da pessoa, na medida em que ela não consegue identificar seus proje- 
João Feres Jr.

tos de auto-realização como algo de valor para a comunidade onde está inserida.

Baseado nessa tipologia das formas de desrespeito, Honneth constrói uma tipologia positiva das formas de reconhecimento. $\mathrm{O}$ autor argumenta que se a falta de reconhecimento fere a auto-estima individual (ou grupal), o reconhecimento mútuo é a maneira pela qual o sujeito é capaz de construir uma imagem positiva de si mesmo, adquirindo, assim, positividade moral e capacidade de ação.

A primeira forma de reconhecimento - a que se refere ao respeito à integridade corporal da pessoa - corresponde à afeição e ao encorajamento que ela recebe daqueles que lhe são próximos. Honneth informa-nos que o jovem Hegel, durante a sua fase romântica em Jena, chamou-a simplesmente de "amor". O senso de segurança corporal e autoconfiança afetiva criado pelo reconhecimento dos sentimentos e necessidades da pessoa é, conforme Honneth, um pré-requisito psicológico para o desenvolvimento de outras atitudes de respeito próprio. Contudo, dado que esse reconhecimento advém daqueles que nos são próximos, membros da família, amigos e parceiros amorosos, aqueles que Taylor chama de "significant others", ele só pode gerar uma moral particular, ou melhor, restrita ao círculo fechado daqueles que compartilham essa afeição.

A segunda forma equivale ao reconhecimento do cidadão, por parte dos outros cidadãos, como membro pleno daquela comunidade e, portanto, como possuidor dos mesmos direitos e deveres que cabem a qualquer outro cidadão. Segundo Honneth, essa relação de reconhecimento é investida de um caráter cognitivo ausente na forma anterior, pois através dela os sujeitos apreendem a lei em seus dois sentidos, como conjunto de normas específicas da sociedade à qual pertencem e como princípio universalizante de regulação das relações humanas.

A terceira e última forma de reconhecimento corresponde ao respeito e estima pelo estilo de vida que constitui parte fundamental da biografia de cada indivíduo. Do ponto de vista da pessoa, isso corresponde à percepção de que suas escolhas individuais, qualidades e habilidades são valorizadas pela sociedade como sua contribuição autêntica. Para Honneth, essa forma de reconhecimento pressupõe a anterior, ou seja, o reconhecimento universal dos direitos e deveres. Ao mesmo tempo, ele adiciona ao mero aspecto cognitivo desse reconhe- 
cimento um elemento emocional na forma da solidariedade e da simpatia. Honneth defende que esse tipo de reconhecimento funciona através do princípio de diferenças igualitárias, ou seja, da idéia de que as pessoas são diferentes, mas não desiguais. Honneth conclui que a moralidade, se entendida como uma instituição que visa à proteção da dignidade humana, deve defender a "reciprocidade do amor, o universalismo dos direitos e a igualdade da solidariedade contra os ataques da força e da repressão" (idem:196).

O subtítulo de "Integrity and Disrespect", de Honneth, pode ser traduzido por "princípios de uma concepção moral baseada na teoria do reconhecimento". Como o nome indica, por via desse artigo, o autor embarca no empreendimento ambicioso de propor uma concepção moral inovadora e sistemática. Contudo, pensamos que é exatamente a partir de seu propósito mais geral que o esforço de Honneth deve começar a ser criticado, pois a proposta peca pela falta de inovação e, conseqüentemente, pela incompletude do sistema.

Por que "falta de inovação"? Porque o problema da moral, da razão prática, deve ser colocado sempre no presente, e, portanto, não pode prescindir de uma leitura crítica desse presente. Ora, vejamos, para Hegel, a idéia de Sittlichkeit tem como pressuposto necessário a autonomia política, entendida como a capacidade de um povo para viver de acordo com seus costumes e elaborar suas próprias leis - pressuposto este fundamental à teoria republicana, de Aristóteles a Carl Schmitt. Mesmo considerando o estado fragmentário dos principados alemães à época de Hegel, é compreensível que ele tenha, sob a influência dos ideais revolucionários franceses e do romantismo nacionalista alemão, desenhado uma teoria política em que o Estado-nação fosse o horizonte ético da condição humana (individual e coletiva): "a marcha de Deus na terra" (Hegel, Knox et alii, 1955, § 258). Porém, após dois séculos e três guerras mundiais ${ }^{5}$, a decadência do imperialismo europeu e a ascensão do império americano, nós, seres no presente, não podemos compartilhar de uma visão tão ingênua ${ }^{6}$. Qual Estado-nação no mundo de hoje tem autonomia suficiente para que a idéia hegeliana de Sittlichkeit ainda faça sentido? Os EUA são, de longe, o mais forte candidato. Os países ditos desenvolvidos da Organização de Cooperação e de Desenvolvimento Econômicos - OCDE, de onde provém grande parte dos teóricos do reconhecimento, gostariam muito de ser "reconhecidos" como tal. Devemos notar, porém, que a autonomia política (e portanto ética) desses países perante os 
EUA, depois da Segunda Guerra Mundial, ficou muito reduzida. Isto é particularmente - e também ironicamente - verdadeiro para a Alemanha de Honneth.

Nosso intuito aqui, porém, não é destruir totalmente essa teoria do reconhecimento, mas apenas desconstruí-la até um ponto a partir do qual ela possa ser radicalmente reconstruída. Proponho, portanto, que deixemos de lado, por enquanto, os países desenvolvidos ancilares e seus porta-vozes com seus sonhos de glória, e dediquemo-nos a pensar o problema do reconhecimento no contexto da nossa condição de brasileiros, não no que ela tem de mais particular, mas apenas levando em conta seu alto grau de heteronomia - uma característica compartilhada em maior ou menor grau pela maioria da população do planeta. O caso da nossa vizinha Argentina, onde o presidente ameaçou renunciar caso o Congresso não aprovasse medidas propostas pelo FMI e depois, a mando do próprio FMI, tentou forçar o Senado a anular uma lei que pune a evasão de riquezas do país, é apenas um exemplo mais recente do tipo da heteronomia a que me refiro. Sem precisar citar os golpes militares de um passado não tão distante, podemos juntar a esse exemplo recente de heteronomia a tentativa de golpe na Venezuela, a ascensão da Aliança do Norte no Afeganistão e a condição a que está submetido o povo palestino.

Precisamos, porém, fazer aqui uma ressalva. Não pretendemos sugerir que nossa condição é exclusivamente heterônoma, ou seja, que não há espaço algum para um debate ético-político no Brasil. Só queremos frisar que o forte componente de heteronomia de nossa condição faz com que não possamos aceitar o modelo de reconhecimento proposto por Honneth sem antes submetê-lo a uma profunda revisão crítica. $\mathrm{O}$ propósito principal deste artigo é, sem abandonar o problema do reconhecimento, propor um outro modelo teórico que dê conta da heteronomia de nossa condição, ao mesmo tempo que possa também ser usado no contexto do debate "republicano" originalmente elaborado pelos teóricos das "democracias do Atlântico Norte".

\section{II}

Na atualidade, as críticas mais duras à filosofia de Hegel e de seus seguidores provêm do campo identificado, muitas vezes pejorativamente, como pós-moderno: nietzschianos de várias cores, autores que estudam o colonialismo e a condição pós-colonial, feministas, 
teóricos das questões de gênero, estruturalistas, pós-estruturalistas etc. Contudo, o autor que utilizaremos (de maneira assumidamente instrumental, mas não abusiva) como alavanca para organizarmos nosso modelo alternativo é estranho ao campo pós-moderno. Trata-se de Reinhart Koselleck, que junto com Otto Bruner e Werner Conze editou a coleção alemã História dos Conceitos Básicos (Geschichtliche Grundbegriffe), o trabalho mais detalhado e extenso de história conceitual de que se tem notícia ${ }^{7}$. A formação filosófica e historiográfica de Koselleck deu-se em Heidelberg sob a influência de Hans Georg Gadamer, Martin Heidegger, Karl Löwith e Carl Schmitt ${ }^{8}$. Sua obra compõe-se principalmente de ensaios sobre a história de conceitos específicos, muitos deles verbetes da Geschichtliche Grundbegriffe, e artigos sobre metodologia e filosofia da história. A este último grupo de trabalhos pertence o texto "A Semântica Histórico-Política dos Contraconceitos Assimétricos", a fonte principal de material para o trabalho de (re)construção que propomos aqui.

Nesse texto, Koselleck elabora um estudo histórico e teórico de formações conceituais que foram usadas por grupos de pessoas como forma de identificação mútua e, portanto, de exclusão dos outros. Para Koselleck, o uso desse tipo de conceito é uma forma de ação política.

"No sentido que damos aqui, um conceito não denota simplesmente a ação, ele marca e cria sua unidade. O conceito não é somente um sinal indicativo da ação, mas também um fator dessa ação em agrupamentos políticos e sociais" (Koselleck, 1985:160).

A adesão de Koselleck ao pragmatismo lingüístico é clara na passagem acima.

Segundo Koselleck, essas formações geralmente ocorrem na forma de "pares de contraconceitos assimétricos". Cada par é composto por um conceito positivo e um negativo, sendo este definido em mera oposição ao elemento positivo. O adjetivo "assimétrico" provém do fato de a relação de definição não ser mútua: enquanto o Eu define o Outro como pura negação de sua auto-imagem, o Outro não se reconhece naquela definição. Aí reside um problema capital de reconhecimento, pois o Outro toma a definição que lhe é impingida como ofensa, insulto e/ou privação. Estamos, portanto, em um terreno muito familiar, pois Koselleck, assim como Honneth, está interessado em examinar o desrespeito como fenômeno lingüístico. 
João Feres Jr.

O primeiro par histórico de contraconceitos estudado por Koselleck é hellenos / barbaros na Grécia clássica.

"Os bárbaros não eram simplesmente considerados não-gregos ou estrangeiros, mas, enquanto estrangeiros, eram de fato definidos negativamente como: covardes, grosseiros, glutões, brutos etc. O nome de um povo - hellenos - torna-se o contraconceito para todos os outros, que são agrupados sob um nome coletivo que significa somente o contrário de 'hellenos'. Assimetria é, portanto, semanticamente, baseada no contraste consciente de um nome específico com uma classificação genérica" (idem:166).

Koselleck emprega a noção de horizonte de expectativas para denotar os efeitos cognitivos abertos pelo uso desses conceitos ${ }^{9}$. Para ele, o caráter negativo do campo semântico que define o Outro predispõe o Eu a interpretar evidências empíricas como sinais que confirmam seus "preconceitos". No caso da Grécia clássica, "contato com comerciantes estrangeiros, a massa de escravos, a devastação dos campos gregos promovida pelos invasores persas e experiências similares podiam ser generalizados de maneira acrítica" (ibidem).

Do ponto de vista político, o horizonte de expectativas gerado pela semântica do par hellenos / barbaros permitia aos gregos justificar a escravização daqueles vistos como bárbaros e/ou a submissão de comunidades bárbaras ao governo de déspotas gregos (Aristotle, 1958 $)^{10}$. Ao argumentar que o bárbaro é um "escravo por natureza", Aristóteles nos dá uma amostra clara das expectativas limitadas abertas aos bárbaros na sociedade grega. Devemos salientar que, nesse contexto semântico, a condição inferior do bárbaro não estava sujeita a modificações introduzidas pela passagem do tempo. Ou seja, não havia uma expectativa de transformação futura dos bárbaros em pessoas civilizadas.

O advento do cristianismo criou novas formas de distinção que ultrapassavam os limites semânticos do par hellenos / barbaros. A principal forma de oposição do mundo cristão cristalizou-se em torno do par contraconceitual cristão/ pagão. No evangelho, São Paulo deixa claro que só há duas formas de conduta humana: aceitar a doutrina cristã e viver de acordo com a escritura, ou rejeitá-la completamente. O caráter assimétrico dessa concepção é explícito, pois o pagão é definido apenas por aquilo que ele não é: cristão. Assim como barbaros, o contraconceito "pagão" está associado no pensamento cristão a conteú- 
dos semânticos que expressam a falta ou imperfeição de costumes, hábitos e tradições que definem o cristianismo. Porém, o horizonte de expectativas aqui assume um caráter fortemente temporal, pois, na doutrina cristã, a possibilidade da conversão futura do pagão ao cristianismo sempre está aberta. Ou seja, o cristão crê na possibilidade de um mundo futuro inteiramente cristão, onde a abominação que é a vida pagã deixe de existir. Essa expectativa foi usada para justificar a ação dos cristãos contra pagãos. Santo Agostinho conclui que, enquanto a perseguição de cristãos por parte dos pagãos é injusta, o contrário é justificável. Em nome do triunfo cristão, europeus do medievo empreenderam conversões forçadas, saques, invasões e massacres. Na prática, a eliminação do estilo de vida do pagão muitas vezes redundou na eliminação física dos próprios pagãos.

Koselleck chama a atenção para o fato de que o surgimento da oposição cristão/ pagão não significou o desaparecimento da oposição que lhe precedeu, hellenos / barbaros. Pelo contrário, os dois tipos de oposição foram articulados, alargando assim o arsenal semântico disponível para se representar o Outro. Os modos de se menosprezar o estilo de vida dos bárbaros podiam sempre ser adaptados para se referir aos pagãos. O termo bárbaro converte-se em um adjetivo usado para se atribuir uma generalidade negativa ao nome de povos pagãos: sarracenos, ávaros, húngaros, eslavos ou turcos.

Por fim, Koselleck analisa as oposições homem/desumano (Mensch/Unmensche) e super-homem/subhomem (Ubermensch/Untermensch), ambas geradas a partir do campo semântico da noção iluminista de humanidade. Aqui, a narrativa koselleckiana volta-se para os detalhes da história desses conceitos na Alemanha, no período que vai do final do século XVII à Segunda Guerra Mundial. Por razões de concisão e clareza, vamos expor somente a parte dessa discussão que diz respeito ao par ariano/não-ariano - uma versão da oposição Ubermensch/Untermensch que ganhou força política durante o Terceiro Reich. Segundo Koselleck,

“O não-ariano é meramente uma negação de uma determinada posição e nada mais. A aplicação do conceito de ariano não está contida no conceito de ariano. O mesmo pode se dizer de 'não-ariano'. Essa situação define uma forma de negação elástica que fica à disposição daqueles que têm o poder de regular os conteúdos lingüísticos e preencher conceitos vazios [...]. Pela primeira vez, o par lingüístico foi usado de 
João Feres Jr.

maneira instrumental por aqueles com poder de regular a língua" (Koselleck, 1985:196).

O autor admite que essa oposição produz a expectativa da eliminação do não-ariano no futuro. Contudo, a exploração que Koselleck faz da semântica do par ariano/não-ariano é por demais superficial e, portanto, imprópria para ser assimilada à nossa tipologia das formas de desrespeito sem antes ser reinterpretada e modificada.

Por fim, Koselleck observa que pares contraconceituais têm um caráter duplo de particularidade histórica e estrutura modelar. Se, por um lado, cada par é produto de um contexto histórico específico, suas estruturas semânticas são transmitidas e assimiladas pelos novos pares que o sucederam. Nessa concepção, a história dos conceitos deve ser compreendida como um adensamento semântico e onomasiológico, em que formas de experiência do passado são transmitidas às gerações futuras através do meio lingüístico (idem). Essa acumulação permite a ocorrência da contemporaneidade do não contemporâneo, um termo que Koselleck cunhou para se referir à coexistência no "presente" de formas lingüísticas (e, portanto, espaços de experiência) produzidas em momentos históricos distintos.

\section{III}

Apesar de sua riqueza e sofisticação, a teoria de Koselleck não pode ser integrada como um todo ao nosso projeto de construção de uma tipologia do desrespeito. Para darmos continuidade a este trabalho, devemos suspender o caráter histórico da narrativa koselleckiana e retrabalhar os atributos modelares de suas oposições contraconceituais. Por que o caráter histórico deve ser suspenso? Ora, o texto de Koselleck tem como pano de fundo uma macronarrativa da história do Ocidente que começa na Grécia antiga e termina na Alemanha do Terceiro Reich e de Carl Schmitt. Se nosso modelo das formas de desrespeito pretende superar as limitações republicanas do modelo de Honneth, não podemos atribuir um caráter universal à macronarrativa que Koselleck nos oferece, pois ela é, de fato, baseada na posição nacional alemã. Ademais, a nosso ver, Koselleck explora de maneira um tanto ligeira as implicações semânticas e modelares de cada oposição contraconceitual, particularmente nos casos cristão/pagão e ariano/não-ariano. 
Seguindo nosso plano de ação, de cada par de contraconceitos identificados pelo autor, destilaremos um tipo básico de oposição assimétrica que corresponde à sua característica modelar mais original. Oposição assimétrica nada mais é do que uma das formas semânticas que o desrespeito pode assumir quando articulado através da linguagem. Portanto, nossa tipologia das formas de desrespeito será também uma tipologia de formas de oposição assimétrica. Do par hellenos/barbaros deduzimos a oposição assimétrica cultural, ou seja, a forma de desrespeito que corresponde à descrição do Outro em termos de costumes e práticas que são meramente a reflexão negativa de uma auto-imagem.

Para Koselleck, a oposição hellenos / barbaros é definida exclusivamente em termos culturais (modos de vida, hábitos e costumes). Apesar de o sentido geral dessa interpretação nos parecer correto, pois a evidência textual aponta realmente para a dominância da oposição cultural, há na concepção grega alguns traços do que chamaríamos hoje de oposição racial, ou seja, da atribuição de aspectos culturais negativos a características físicas e fisionômicas. Ao apresentar a teoria da escravidão natural na Política, Aristóteles discute a possível correlação entre barbarismo e características físicas inferiores (Aristotle, 1958:1254b). Apesar de Aristóteles, por fim, rejeitar tal inferência, o fato de ele ter articulado esse problema naquele contexto histórico-lingüístico sugere a possibilidade de que tal raciocínio tenha existido na Grécia antiga. Contudo, este é de fato um problema menor na interpretação koselleckiana. Ademais, da maneira como a propomos, a oposição assimétrica cultural pode ser generalizada como forma de desrespeito independentemente da pertinência da interpretação histórica do caso grego.

A oposição assimétrica cultural pode ser encontrada, por exemplo, em uma das definições do termo "Latin" apresentadas pelo Oxford English Dictionary: "proud, passionate, impetuous, showy in appearance [...], sometimes somewhat dismissive (Simpson e Profitt, 1997)"11. O sentido negativo desses termos é óbvio. O orgulho aqui significa uma forma exagerada de auto-estima. O caráter passional é claramente uma alusão à irracionalidade daqueles que são dominados pelas paixões. Impetuosidade é a característica irracional daquele que age por impulso. A pessoa que se preocupa com as aparências é vã e fútil. $\mathrm{O}$ sujeito arisco é aquele em quem não se pode confiar. Ademais, esses 
insultos correspondem à negação exata de uma auto-imagem anglo-saxã de racionalidade, disciplina, correção e caráter.

Chamamos a segunda forma de desrespeito de oposição assimétrica temporal. Ela é relacionada ao par contraconceitual cristão/pagão, mas de maneira indireta e incompleta. Koselleck limita sua análise a autores do cristianismo primitivo e medieval que permaneceram fiéis a uma noção temporal dominada pela eminência escatológica e, por conseguinte, deixa de notar que o desenvolvimento mais profícuo da noção temporal cristã se dá quando de sua secularização a partir do começo da Idade Moderna. Os pioneiros desse movimento de secularização foram os tomistas espanhóis Bartolomeu de las Casas e José de Acosta - autores que se engajaram na exploração etnológica dos povos do Novo Mundo ${ }^{12}$. Para determinar o "lugar" desses novos povos no mundo, eles criaram um sistema de classificação comparada de todas as sociedades de que os europeus tinham notícia, incluindo povos e civilizações já extintos. Nesse sistema, a cristandade católica européia ocupa o ápice de uma escala de desenvolvimento e é, ao mesmo tempo, a medida pela qual outros povos são classificados. Culturas extra-européias são, dessa maneira, identificadas com povos europeus do passado, criando a possibilidade de se pensar diferença cultural em termos de primitivismo, atraso ou retardamento, isto é, em termos de diferença temporal ${ }^{13}$. Essa possibilidade, aberta pelas etnologias de Las Casas e Acosta, se consolidou com o advento de teorias históricas seculares do progresso contínuo na França iluminista ${ }^{14}$. Nelas, a escatologia cristã foi finalmente abandonada, enquanto a noção eurocêntrica de progresso moral e material se tornou o principal instrumento etnológico de classificação do Outro.

Vale ressaltar que cada um desses movimentos de secularização da concepção histórico-etnológica (tomismo espanhol e iluminismo) coincidiu com uma onda de expansão mundial do colonialismo europeu. Essa coincidência não é aleatória, pois, nos dois casos, as novas etnologias serviram para justificar a submissão de povos definidos como "atrasados" ou "imaturos" aos próprios europeus. O paternalismo da retórica colonial, da mission civilisatrice, só pôde ser articulado tomando como base tais etnologias.

Como já declaramos, o ponto de partida de nosso esforço de construir uma tipologia das formas do desrespeito é o presente. E neste presente, a forma de desrespeito que se articula como oposição temporal as- 
simétrica é expressa majoritariamente através de etnologias do desenvolvimento material e moral, e não da expectativa cristã primitiva de uma solução escatológica para o problema do Outro. Essa é uma forma de desrespeito das mais sérias, pois transforma o Outro (o atrasado) em objeto da ação do Eu (desenvolvido). A teoria da modernização desenvolvida na academia americana durante as décadas de 1950 e 1960 é inteiramente baseada na oposição temporal assimétrica de um Eu ocidental, americano, capitalista-protestante, que é desenvolvido, a um Outro tradicional, que é simplesmente definido pela falta desses atributos. Essa teoria serviu de base para uma série de políticas externas americanas, da Aliança para o Progresso à remoção forçada de centenas de milhares de camponeses vietnamitas de suas moradias na zona rural para grandes cidades ${ }^{15}$.

A terceira forma de desrespeito, oposição racial assimétrica, é derivada das idéias de Koselleck de maneira ainda mais indireta do que a anterior. Koselleck não compara a semântica do par ariano/não-ariano aos pares que o precederam. Façamos o serviço em seu lugar. Assim como "bárbaro", o conceito de não-ariano foi usado para se referir genericamente ao Outro, de maneira a apresentá-lo como moralmente inferior. Assim como no par cristão/pagão, a oposição ariano/não-ariano gerava a expectativa de solução para o problema do Outro no futuro, que, nesse caso, correspondia à purificação do Lebensraum alemão de elementos não-arianos e à submissão do resto do mundo ao domínio geopolítico alemão. No entanto, o campo semântico desse par contém elementos estranhos aos dois outros que o precederam (hellenos/barbaros e pagão/cristão). Essa "novidade" corresponde à articulação da diferença em termos de raça.

Durante o século XIX, o conceito de "raça" assumiu uma importância político-ideológica sem precedentes para as ideologias nacionalistas que sustentaram a consolidação dos Estados-nação europeus, principalmente na Alemanha, França e Inglaterra. Segundo Hannaford (1996), naquele período, o conceito de raça era usado para exprimir de maneira sintética diferenças que podiam ser biológicas, lingüísticas e/ou culturais. Todavia, o autor deixa de notar que esses componentes da noção de raça não são eqüipotentes. Isto é particularmente verdadeiro para a maneira como o termo é empregado nos dias de hoje. Tanto em português com em inglês, o termo "raça" (race) não é totalmente destituído de referências culturais, ou seja, no uso comum dessas línguas, culturas específicas são identificadas com determina- 
das raças. O que parece escapar a Hannaford, e também a Koselleck, é que o componente biológico, expresso através de referências a aspectos físicos, fisionômicos e psicológicos, é, no presente, o elemento determinante da noção de raça.

Parece-nos correto afirmar que "raça" é uma construção sociocultural. Ao mesmo tempo, porém, não podemos deixar de notar que o termo é usado para significar algo que está além (ou aquém) da cultura (aspectos físicos, fisionômicos e psicológicos). A percepção da diferença racial como oposição assimétrica cria um universo de expectativas próprio, em que o problema do Outro não pode ser "resolvido" pela assimilação cultural - solução que sempre esteve no horizonte dos projetos colonialistas. Dado seu caráter biologizante, a oposição racial assimétrica aponta para a solução desse problema na forma do controle radical do corpo do Outro. Os exemplos práticos desse tipo de desrespeito são a solução final nazista, os guetos étnicos das grandes cidades americanas, o regime sul-africano do apartheid etc.

Um exemplo claro de articulação retórica dessa forma de desrespeito é dado pelo discurso proferido no Congresso americano pelo deputado do Estado de Nova Iorque Washington Hunt quando da discussão sobre a anexação de partes do território mexicano durante a guerra americano-mexicana (1846-1848):

“Pensem no tipo de população que a anexação desses territórios trará para nossa confederação. Devemos preparar-nos para receber uma massa incongruente de espanhóis, índios e mexicanos mestiços - uma mistura de raças que não vai poder usufruir ou administrar nossas instituições livres. Homens de sangue diferente e língua diferente, que não devem se misturar com o nosso povo em pé de igualdade política e social" (Schoultz, 1998:32).

A assimetria da comparação é patente: de um lado, americanos brancos anglo-saxões, de outro, um coletivo de gente escura (não-brancos). Ao final, os territórios mexicanos foram anexados à Federação americana, mas a maioria daquelas populações "indesejáveis" foi exterminada no processo de apropriação, seja pelo exército americano, seja pelos colonos. A expectativa criada por essa percepção racial altamente assimétrica, da qual Hunt era somente um porta-voz, moldou o futuro. 
Através da noção da contemporaneidade do não contemporâneo, Koselleck identifica o sintoma da sobreposição cumulativa dos campos semânticos de pares de contraconceitos: o cristão pôde usar o arsenal pejorativo que os gregos criaram para se referir aos bárbaros e combiná-lo com sua noção de temporalidade; os racistas podem se servir dos dois para somar à distinção biológica aspectos culturais e temporais (ex: raças mais primitivas têm culturas menos evoluídas). A idéia da contemporaneidade do não contemporâneo, de fato, parece uma hipótese interessante, porém, ao suspendermos a macronarrativa histórica que orienta o texto de Koselleck, acabamos por descartar o padrão de acumulação semântica específico que ela identifica (dos gregos aos alemães, passando pelos cristãos). Resta-nos substituí-la por uma nova categoria: a "tradutibilidade das formas de oposição assimétrica", definida como propriedade pela qual certas expressões lingüísticas são capazes de denotar mais de uma forma de desrespeito. Ou seja, vocabulários usados na descrição de uma determinada forma de oposição assimétrica, não raro, podem sugerir outras. Por exemplo, a palavra temperamento tem matizes culturais e raciais; categorias sociocientíficas como "patriarcalismo" e "feudalismo" têm nuanças culturais e temporais.

A existência de possibilidades de tradução depende não somente do significado intersubjetivo de cada um dos conceitos utilizados, mas também da articulação retórica empregada no material a ser examinado. Termos que usualmente não são associados a uma determinada forma de desrespeito podem ser semanticamente contaminados pela proximidade de outros termos geralmente associados àquela forma. Em suma, diferentemente da "contemporaneidade do não contemporâneo", que é definida como característica intrínseca e inelutável do processo histórico, a "tradutibilidade das formas de oposição assimétrica" é uma propriedade hipotética que só pode ser confirmada através da análise de cada caso, prescindindo, assim, de qualquer entendimento prévio sobre os rumos da "história universal".

\section{IV}

Nossa tipologia das formas de desrespeito não é incompatível com a tipologia negativa de Honneth. De certa maneira, as oposições assimétricas cultural e temporal podem ser vistas como casos particulares da terceira forma de desrespeito identificada pelo autor - aquela que degrada o estilo de vida da pessoa. Porém, ao empreender uma 
análise detalhada das articulações lingüísticas (ou retóricas) do desrespeito, nosso modelo é capaz de revelar aspectos que a teoria de Honneth sequer vislumbra. Na verdade, as três formas de desrespeito identificadas por nós podem ser usadas (e foram usadas), individualmente ou em conjunto, para justificar todas as três formas de Honneth (abuso físico, negação de direitos e degradação do estilo de vida). Por meio da noção da tradutibilidade das formas de desrespeito, podemos examinar as várias combinações dessas formas e, portanto, compreender melhor o poder que esses usos lingüísticos têm de rebaixar o Outro a uma condição de inferioridade submissa.

Essa solução também nos parece vantajosa quando comparada à concepção do problema do reconhecimento segundo o cânone do republicanismo hegeliano. Primeiro, ela nos permite identificar o desrespeito, expresso no uso lingüístico corrente de oposições assimétricas, em situações inacessíveis à concepção republicana, como, por exemplo, quando o desrespeito ocorre em comunidades lingüísticas nas quais o Outro não é parte significativa. Essa função nos ajuda a desvendar conexões entre nossa condição de heteronomia e o desrespeito em um contexto internacional altamente assimétrico. Se a identificação desse desrespeito não nos permite de pronto alterar a situação de heteronomia, ela pelo menos nos ensina a assumir uma postura crítica em relação a discursos que reproduzem as mesmas formas de desrespeito.

Segundo, nossa tipologia das formas de desrespeito pode também ser aplicada ao contexto limitado do Estado-nação democrático liberal, servindo a todos aqueles que se sentem vítimas de desrespeito como ferramenta de resistência e desconstrução de discursos que lhes parecem insultantes. Como contribuição ao embate ideológico e político, nossa proposta nos parece superior à oferecida pelo republicanismo hegeliano (seja de Taylor ou Honneth), pois permite que a identificação do desrespeito se torne independente da afirmação de uma identidade autêntica. Através desse instrumental analítico, a pessoa, ou grupo de pessoas, pode localizar e rejeitar formas lingüísticas que lhe atribuam um caráter de imaturidade, primitivismo ou inferioridade, sem ter que assumir publicamente qualquer identidade específica. Ademais, as pessoas ou grupos que desejam afirmar publicamente uma identidade podem utilizar-se dessa tipologia da mesma maneira. Em suma, nossa tipologia pretende servir de ferramenta políti- 
co-ideológica na luta pela realização, na prática, da igualdade da cidadania liberal expressa formalmente na letra da $l \mathrm{ei}^{16}$.

O caráter eminentemente negativo de nossa tipologia é particularmente apropriado ao contexto brasileiro onde, para o bem ou para o mal, os rótulos raciais e étnicos definidos no Primeiro Mundo não se reproduzem de maneira tão nítida ou similar. Ademais, a idéia de autenticidade que anima a teoria multicultural republicana produz efeitos perversos também no contexto dos países "desenvolvidos". Por exemplo, nos EUA, programas como affirmative action e outros benefícios proporcionam incentivos àqueles que se identificam como minorias. Contudo, ao se identificar publicamente dessa maneira, a pessoa está explicitamente assumindo o caráter subalterno de sua posição. Isto leva a uma contradição prática na qual, para se tornar igual, a pessoa deve apresentar-se como inferior. Resta-nos saber se esse tipo de programa é capaz de superar essa contradição.

Por fim, nosso modelo evita a conclusão hegeliano-republicana, clara em Honneth, de que o reconhecimento depende da formação de uma autoconsciência saudável. Honneth acredita que essa concepção positiva sirva de base para que todos possam lutar politicamente pelas condições que lhes proporcionem uma vida familiar e afetiva sadia, direitos negativos iguais e reconhecimento cultural (ver Honneth, 1992). No entanto, tal conclusão parece depender de um padrão de normalidade que, imediatamente, se constitui como critério de exclusão das pessoas que, de alguma maneira, falharam na formação "correta" de sua autoconsciência. Em outras palavras, a tipologia positiva de Honneth pode constituir-se, na prática, em instrumento de promoção de mais desrespeito.

O reconhecimento, como forma positiva, deve ser um produto do engajamento concreto das pessoas na política, e não um valor a ser fixado através da especulação teórica. O esforço em determiná-lo teoricamente é contraditório porque nega os princípios de liberdade e igualdade democrática sobre os quais o próprio reconhecimento se assenta. Conseqüentemente, a teoria deve ser usada para ajudar-nos a resistir às formas de desrespeito, criando ferramentas úteis ao debate político, tenha esse como objeto a comunidade nacional ou os discursos que legitimam poderes imperiais e transnacionais.

(Recebido para publicação em junho de 2002)

(Versão definitiva em agosto de 2002) 


\section{NOTAS}

1. Por falta de melhor termo, usarei aqui "desrespeito" ou "falta de reconhecimento" como antônimo de "reconhecimento". Em inglês criou-se o neologismo "misrecognition" para denotar a falta de reconhecimento (recognition). O termo usado por Honneth no original alemão é "Anerkennung", que significa não somente reconhecimento puro e simples, mas também a atribuição de qualidades positivas através desse ato. Assim como o português, o alemão também não tem um antônimo perfeitamente simétrico para o termo. Honneth usa "Mißachtung", que se traduz por desrespeito, mas que pode também carregar significados mais negativos como insulto, humilhação, degradação, privação de liberdade e mesmo agressão física. Ver "Translator's Note", em The Struggle for Recognition: The Moral Grammar of Social Conflicts (Honneth, 1995).

2. Todas as traduções de citações extraídas de originais em inglês são de minha autoria.

3. O pragmatismo lingüístico, às vezes referido como linguistic turn, é hoje em dia uma posição epistemológica de grande força nos meios acadêmicos da Europa continental e de países anglófonos. O livro Philosophical Investigations, de Wittgenstein (1953), é geralmente identificado como a obra fundadora dessa abordagem.

4. Em The Struggle for Recognition, Honneth expõe claramente as raízes hegelianas de sua tipologia do reconhecimento, que é, de fato, inspirada na obra produzida pelo jovem Hegel em Jena, quando ainda sob a influência do pós-kantismo romântico de Schelling e Hölderling e da filosofia neokantiana de Fichte (ver Pinkard, 2000). Honneth usa como fonte da filosofia do jovem Hegel o conjunto de obras que precederam a publicação da Fenomenologia do Espírito. São elas: O Sistema da Eticidade (System der Sittlichkeit, 1802/03), Primeira Filosofia do Espírito (System der spekulativen Philosophie, 1803/04), e Jenaer Realphilosophie (1805/06).

5. Tomo aqui a liberdade de contar a Guerra Fria como a Terceira Guerra Mundial, pois essa se estendeu verdadeiramente por todo o planeta. Infelizmente, ainda não contamos com estatísticas confiáveis quanto ao número de mortos produzidos por esse conflito.

6. A diferença entre imperialismo e império feita aqui não corresponde à distinção original elaborada por Hardt e Negri (2000). Para estes autores, os imperialismos europeus assentavam-se em bases nacionais, enquanto o império do presente é o único verdadeiramente global. Coerentemente, para Negri e Hardt, a expressão "império americano" não é verdadeira, afirmação com a qual, obviamente, discordamos, pois os mecanismos políticos de tomada de decisão no contexto imperial atual são altamente dependentes da dinâmica política doméstica americana. O governo Bush tem dado mostras abundantes dessa triste realidade.

7. A Geschichtliche Grundbegriffe (Koselleck et alii, 1972/1997) é uma obra de aproximadamente nove mil páginas, dividida em nove volumes, com um total de 115 verbetes dedicados a conceitos específicos (Richter, 1995).

8. Uma introdução curta mas informativa à biografia intelectual de Koselleck foi escrita pelo tradutor Keith Tribe em Futures Past (Koselleck, 1985). Para um exame mais detalhado do projeto da Geschichtliche Grundbegriffe, ver Richter (1995). 


\section{Contribuição a uma Tipologia das Formas de Desrespeito...}

9. A noção de horizontes de expectativas advém da teoria hermenêutica de Gadamer (1995). Um outro exemplo claro e brilhante do uso dessa noção pode ser encontrado em Ricoeur (1981).

10. Melvin Richter (1990) explora com detalhe as conexões entre os conceitos gregos de despotismo, escravidão e barbarismo.

11. Tradução aproximada: orgulhoso, passional, impetuoso, exibido e, algumas vezes, um pouco arisco. A citação foi mantida na língua original com o intuito de preservar o conteúdo semântico dos adjetivos, que é invariavelmente alterado em qualquer tradução.

12. Para uma análise mais pormenorizada das contribuições de Las Casas e Acosta, ver Pagden (1982).

13. O antropólogo Johannes Fabian (1983) cunhou o termo "não-concomitância" para descrever a percepção de que pessoas, na qualidade de membros de uma determinada comunidade, possam existir no presente e, ao mesmo tempo, no passado. Para uma genealogia detalhada da noção de "não-concomitância", ver Feres Jr. (2002).

14. O exemplo mais acabado desse tipo de concepção histórica se encontra em Condorcet (1988). Para uma discussão panorâmica do desenvolvimento de teorias históricas do progresso contínuo a partir da escatologia cristã, ver Löwith (1949).

15. Noam Chomsky (1968) descreve em detalhe a participação de "grandes nomes" das ciências sociais americana, como W. W. Rostow e Samuel Huntington, na concepção e implementação de políticas de urbanização forçada no Vietnã. Baseado na premissa de que o comunismo vietnamita era um sintoma da falta de desenvolvimento, Huntington conclui que uma "modernização" acelerada dos camponeses vietnamitas (urbanização forçada) roubaria aos vietcongs sua base de sustenção.

16. Por ser eminentemente negativa, nossa proposta é de pouca valia para as minorias que desejam reclamar direitos especiais para a preservação de sua autenticidade. 
João Feres Jr.

\section{REFERÊNCIAS BIBLIOGRÁFICAS}

ARISTOTLE. (1958), The Politics of Aristotle. New York, Oxford University Press.

CHOMSKY, Noam. (1968), American Power and the New Mandarins. New York, Pantheon.

CONDORCET, Marie-Jean-Antoine-Nicolas de Caritat marquis de. (1988) [1795], Esquisse d'un Tableau Historique des Progrès de l'Esprit Humain/Fragment sur l'Atlantide. Paris, Flammarion.

FABIAN, Johannes. (1983), Time and the Other; how Anthropology Makes its Subject. New York, Columbia University Press.

FERES JR., João. (2002), “Political Philosophy, Ethnology, and Time: A Study of the Notion of Historical Handicap". Kriterion, nำ105, pp. 19-42.

GADAMER, Hans Georg. (1995), Truth and Method. New York, Continuum.

HANNAFORD, Ivan. (1996), Race; the History of an Idea in the West. Baltimore/London, The Johns Hopkins University Press.

HARDT, Michael e NEGRI, Antonio. (2000), Empire. Cambridge, Harvard University Press.

HEGEL, Georg Wilhelm Friedrich, KNOX, T. M. et alii. (1955), The Philosophy of Right. Chicago, Encyclopædia Britannica.

HONNETH, Axel. (1992), “Integrity and Disrespect: Principles of a Conception of Morality Based on the Theory of Recognition". Political Theory, vol. 20, no 2, pp. 187-202.

. (1995), The Struggle for Recognition: The Moral Grammar of Social Conflicts. Cambridge, Polity Press/Blackwell.

KOSELLECK, Reinhart. (1985), Futures Past: On the Semantics of Historical Time. Cambridge/London, The MIT Press.

__ et alii (eds.). (1972/1997), Geschichtliche Grundbegriffe. Stuttgart, Klett-Cotta, 9 vols.

LÖWITH, Karl. (1949), Meaning in History. Chicago/London, Phoenix Books/The University of Chicago Press.

PAGDEN, Anthony. (1982), The Fall of Natural Man: The American Indian and the Origins of Comparative Ethnology. Cambridge/New York, Cambridge University Press.

PINKARD, Terry P. (2000), Hegel: A Biography. Cambridge/New York, Cambridge University Press.

RICHTER, Melvin. (1990), “Aristotle and the Classical Greek Concept of Despotism”. History of European Ideas, vol. 12, nํ2, pp. 175-187.

(1995), The History of Political and Social Concepts: A Critical Introduction. New York/Oxford, Oxford University Press.

RICOEUR, Paul. (1981), Hermeneutics and the Human Sciences. Paris, Cambridge University Press/Éditions de la Maison des Sciences de l'Homme. 


\title{
Contribuição a uma Tipologia das Formas de Desrespeito...
}

SCHOULTZ, Lars. (1998), Beneath the United States: A History of US Policy toward Latin America. London/Cambridge, Harvard University Press.

SIMPSON, John e PROFITT, Michael (eds.). (1997), Oxford English Dictionary, Additions Series. Oxford, Clarendon Press.

TAYLOR, Charles e GUTMANN, Amy. (1994), Multiculturalism: Examining the Politics of Recognition. Princeton, N.J., Princeton University Press.

WITTGENSTEIN, Ludwig. (1953), Philosophical Investigations. New York, Macmillan.

\begin{abstract}
Contribution to a Typology of Forms of Disrespect: Beyond the Hegelian Republican Model

In this article we propose a new typology of forms of disrespect. Based on Axel Honneth's critique of the Hegelian Republican treatment of the issue of recognition, we elaborate an alternative proposal, inspired by the notion of asymmetrical counter-concepts as proposed by Reinhart Koselleck. We identify three basic forms of disrespect as expressed through the use of language, pointing to the horizons of expectations and the practical consequences they generate. Finally, we examine the advantages presented by our typology as compared to that proposed by Honneth, amongst which the possibility of applying this analytical tool to identify forms of disrespect that transcend the borders of the nation-state.
\end{abstract}

Key words: disrespect; heteronomy; asymmetrical oppositions 
João Feres Jr.

\section{RÉSUMÉ}

Apport à une Typologie des Formes d'Irrespect au-delà du Modèle Hégélien et Républicain

Dans cet article, on propose une nouvelle typologie des formes d'irrespect. À partir de la critique du traitement hégélien et républicain dispensé par Axel Honneth à la question de la reconnaissance, on conçoit une alternative, suggérée par la notion de contre-conceptions asymétriques que propose Reinhart Koselleck. On peat y discerner trois formes fondamentales d'irrespect exprimées dans l'usage langagier, indiquant l'horizon des attentes et les conséquences pratiques qu'elles engendrent. Enfin, on compare les avantages de notre typologie par rapport à celle proposée par Honneth, parmi lesquelles la possibilité d'application de cet outil analytique dans l'identification de formes d'irrespect qui dépassent les limites étroites de l'État national.

Mots-clé: d'irrespect; hétéronomie; oppositions asymétriques 